\title{
Engineering Play: Children's software and the cultural politics of edutainment
}

\author{
Mizuko Ito
}

This is a preprint of an article submitted for consideration in DISCOURSE, 2006, copyright Taylor \& Francis; DISCOURSE is available online at http://journalsonline.tandf.co.uk.

The late eighties saw the emergence of a new genre of instructional media, "edutainment," which utilized the capabilities of multimedia personal computers to animate software designed to both educate and entertain young children. This paper describes the production, marketing, and play with edutainment software as a contemporary example of longstanding tensions between the cultural categories of education and entertainment, play and learning. Like prior efforts to wed learning and play, edutainment was founded on the ideal of broadening access to academic learning. Yet as it became a mainstream commercial enterprise, it was increasingly targeted toward accelerating the achievement of successful children. After first describing the industry and marketing context of edutainment, this paper describes cases of play with edutainment software in an afterschool computer club. The analysis utilizes the concepts of "multimedia genre" and "participation genre" to read across sites of production, distribution and consumption to examine how genres of entertainment, education, and edutainment are constituted through the circulation and play with media artifacts. As in the case of the industry and marketing context, instances of play with edutainment titles follow certain genre conventions for engagement. Titles that are based on academic content and modes of engagement, even with a wrapper of entertainment styles, invite a competitive orientation and interaction focused on fulfilling the minimal conditions for moving ahead and getting credit for completion of a task. Unlike more exploratory or construction-oriented software titles, these genres of software are marketed and keyed to the social demands of middle-class achievement.

\section{Introduction}

In the early eighties, a handful of enterprising educators began utilizing the capabilities of multimedia computers to design software that brought together academic content and the interaction styles of computer gaming. In an interview in 2000, Anne McCormick ${ }^{1}$, the founder of The Learning Company (TLC), described the excitement of those early years and the sense that they were creating possibilities for learning that freed it from the institutional constraints of schooling: "We created a new category by working with an Atari game designer and educators ... I didn't want to call it educational because to me that meant schooling, dusty, institutional. That's why I called it The Learning Company not The Education Company." Through the eighties and nineties, titles created by companies like TLC captured the public imagination and became successful commercial ventures. While edutainment software succeeded in becoming an established media form, the process of mainstreaming and adoption has entailed a set of accommodations to existing genres of children's participation with media, as well as resilient structures of social stratification and achievement. The case of edutainment embodies the challenges 
which reformers face in creating new genres of representation and practice that bridge the polarity between schools (education) and recreation (play) that dominant modern childhood.

This essay draws from a more extended analysis of the production, distribution, and consumption of children's software based on three different "multimedia genres" : edutainment, entertainment, and authoring (Ito, 2003). The focus here is on the edutainment genre, and how it involves an imperfectly negotiated truce between the dominant idioms of education and entertainment. After first locating multimedia edutainment in cultural and historical context, I suggest conceptual frameworks of multimedia genres and participation genres to understand how culture gets embodied and "hardened" into certain conventionalized styles of representation, practice, and institutional structure that become difficult to bridge. I also use the concept of genre as a nod to John Seely Brown and Paul Duguid's (1996) notion of genre as a category that cross-cuts form and content, invoking the often implicit social practices and understanding that contextualize a media artifact, "the peripheral clues that crucially shape understanding and use." Although a concept keyed to discursive analysis, I mobilize it in an interdisciplinary frame, using it to refer not only to representation, but also to institutional structures and everyday practice, the ways in which representations are constructed, contextualized, and animated by social and economic structure.

After first examining the genre of edutainment as it operates in software production, distribution, and advertising, the essay then moves to an analysis of contexts of consumption, drawing from video-based study of play at an after-school computer club in California. The central argument is that the genre of edutainment, while utilizing representational genre cues from entertainment, has come to mobilize a participation genre grounded in mainstream models of educational achievement and individuated competition.

\section{Cultural and Historical Contexts of Edutainment}

Edutainment software is contextualized by discourses of childhood, learning and play that have framed earlier media such as children's literature and developmental toys since the early nineteenth century. In his history of the U.S. toy industry, Gary Cross (1997) describes the niche market of learning toys that grew up from the 1930s, differentiating itself from the mainstream novelty-oriented toy markets of the time. These toys were inspired by the popularization of a more scientific model of parenting in the 1900s, and educational researchers such as Jean Piaget and Friedrich Froebel who believed in the educational potential of play. He writes, "As late-nineteenth century society mechanized and prosperity increased, and as parents had less need for children to work, reformers recognized a need to turn the child's play time to productive use" (Cross, 1997, pp. 123124). Ellen Seiter analyzes advertisements in Parents magazine during this period of growth of educational toys from the 20 s to the 50 s. "Parents continually repeated the platitude that play was educationally valuable" (1995, p. 66). "Toys could guarantee joy yet be instruments of hard work and achievement. What more could anyone ask from a commodity?" (Seiter, 1995, p. 67). Similarly, Cross notes that "Play had become the 'work' of children. And work required tools" (Cross, 1997, p. 129). This bourgeois view of childhood play as a privileged and generative site for developing the agency of cultural producer, or "worker," was established in opposition to a hedonistic, "consumptive" or "recreational" view of play that was associated with licensed products and the growing tide of children's "junk culture". Cross suggests, "The ideals of self-directed play, with 
objects of simple design had nothing to do with the appeal of character toys. Educational playthings represented, to middle-class parents, a bulwark against the tide of commercialism and its threat to undermine parental authority and Victorian values" (Cross, 1997, pp. 134-135).

After the ascendancy of television in the fifties the Victorian parental orientation toward childhood discipline and intellectual development has been overshadowed by the influence of a fast-paced, commercial, and fantasy-based children's popular culture. Middle-class attitudes towards restraint and denial in consumption have eroded in the face of television and the ubiquity of children's popular culture. We have been left with an increasingly reified distinction between education and entertainment, separately institutionalized in school disciplines versus commercial amusements, each with distinct genres and class identifications. Among a more educationally conscious sector of the middle-class, however, there is continued resistance to faddish toys in favour of educational toys developed in earlier decades. Other more "progressive" parents believe that they should try to make learning fun. The market niche of non-licensed and educationally-marked children's products, ranging from wooden train sets to classic children's books and Lego blocks become a source of an anti-mainstream cultural capital that unites the anti-commercial sentiments of certain sectors of both the conservative and progressive middle-class.

The efforts of educational software designers in the early eighties were a revival of these longstanding trends in the design of educational playthings. Contrasting the computer to what they considered the "passive" medium of the television, creators and marketers of educational software argue that the medium merges the fast-moving appeal of computational media with active engagement and learning. Like educational toys that originated in the nineteenth century, educational software is seen as a bulwark against video games and repetitive, hedonistic, and violent play. Software produced by companies like TLC are played on computers rather than game consoles, the "good screens" in contrast to the "bad screens" of television (Seiter, 1999, p. 247). Although mainstream commercial licenses are increasingly dominating children's software, companies like TLC have tended to shy away from the commercialism implied in mass licensing, creating their own characters or linking up with public television content such as Blue's Clues and Arthur. Like books, the term "literacy" is often attached to the use of computers, a cultural marking differentiating it as a highbrow and "difficult" media form, structurally set off from "illiterate" forms of media such as television and video games. ${ }^{2}$ In other words, edutainment is a media genre that negotiates between the genres of entertainment and education and the institutional structures of schooling and commercial media.

While multimedia edutainment was founded on the promise of exploding the boundaries between learning and play, home and school, as it matured as an industry and media format, it became subject to genre demands that polarized content toward either schooling or commercial media settings, eventually settling into a small market niche oriented towards school preparatory activities and academic support for achievementoriented families. The edutainment genre brings in styles and characters from television and video games, but it addresses content areas that are associated with school achievement, such as reading, math, and science. Although many of the early innovators in children's software were trying to break the idioms of mainstream schooling and pedagogy, as I will demonstrate in the analysis to follow, the genre of edutainment ended up gravitating towards participation genres that reproduced the existing logic of competitive academic achievement. 


\section{The Industry Context: From education to learning and back again}

At the same time that McCormick was producing software titles such as Gertrude's Puzzles, Rocky's Boots, and Reader Rabbit, other educational researchers at the University of Minnesota were beginning to commercialize products such as Oregon Trail and Number Munchers. The Minnesota Educational Computing Corporation (MECC) was originally funded by the State of Minnesota in 1973, and became a public corporation in 1985, riding the successes of these software titles. Jan Davidson, a former teacher, started her company Davidson \& Associates in 1983, developing titles such as Math Blaster which, in its various incarnations, has been the best selling piece of math software through the years. These software titles, all originally produced for the Apple II, became pioneers in the new market for educational software for home use. While growing out of school-based uses of computers, these new products were designed for the consumer market. They departed from strictly curricular and instructional goals of the majority of school-based software, incorporating visual and narrative elements from popular culture. The late seventies and eighties also saw the founding of experimental efforts such as the Apple Classrooms of Tomorrow (ACOT), the Vivarium project at the Open School in Los Angeles, and programs at the Bank Street College of Education, which piloted these new technologies in experimental educational settings. The Fifth Dimension Afterschool Club project, which I will describe later as a site for my fieldwork, also had roots in this era of experimentation. While products were being commercialized, they were oriented to a small market of like-minded educators and parents.

Most of the early innovators in educational software had backgrounds in formal education before turning to these commercial efforts. These early years in the groundbreaking of the industry were characterized by a sense of optimism and social mission. This period of innovation saw the establishment of the basic formulas and genres of children's software in titles such as Oregon Trail, Reader Rabbit, and Math Blaster that continue to be reproduced and repackaged today in a variety of titles. The learning software industry currently sustains itself on learning adventure games. Games such as Math Blaster and TLC games such as Reader Rabbit and Gertrude's Puzzles embed academic problems and tasks within an adventure game format. Kids progress through a fantasy adventure by solving various puzzles and problems along the way. This format has the benefit of integrating an entertaining adventure storyline with a flexible structure for sequentially presenting problems. All of the current lead products in learning software such as the Jump Start, Blaster, and Reader Rabbit series are based on this model. This model also makes economic sense to developers, as they can reuse the same game engine - the underlying software for creating the virtual world - and plug in different characters, storylines, and problems, thus reducing overall development costs.

As the educational software industry has matured over the past two decades, the ground-breaking approaches of educators such as McCormick and Davidson have been converted into an established industry model that is more formulaic than revolutionary. Both McCormick and Davidson left the companies that they helped create, and both feel that the companies went on to prioritize profit at the expense of educational quality (Revue, 1997). In the eighties, new companies were founded by educators with high ideals and new products were distributed to a small market of like-minded educators and

computer aficionados. The nineties saw the proliferation of PCs, the consolidation of software industries, and the emergence of a mass market in family-oriented software. 
Instead of being sold at specialty computer and hobby shops, by the nineties, most of the volume of children's software was being sold at superstores such as Cosco, Walmart, CompUSA, Toys R Us and Office Depot. Career CEOs had pushed aside company founders, and by the end of the nineties, the children's software industry had largely consolidated under two conglomerates, one headed by Mattel, and the other by media industry giant, Cendant.

A larger market, mainstream retail, and more resource-intensive forms of technology have led, ironically, to the demise of what many have felt to be quality products. Now most development budgets are spent upgrading graphics and sound and developing content in established formulas rather than on developing new models for interaction or game design. Products that have easily-represented marketing "hooks" like a licensed character, established brand, or the claim to transmit strategic cultural capital are easier to disseminate in the current commercial ecology than products with more open-ended, complex, and multi-referential goals. An early product, Oregon Trail, placed academic knowledge in the context of historical simulation, and removed it from the stepwise sorting functions of school assessment. As children consider how best to manage rations and supplies and proceed along a simulated journey with real-world referents, academically relevant content is mobilized as one relevant component of decisionmaking. There is no hierarchical assessment of achievement based on realization of a singular correct outcome. Many currently dominant products, by contrast, put social distinction and assessment back in, tallying markers of progress in a school-relevant way. In marketing materials, parents are told that these products will help their children orient to the competitive demands of school curriculum.

The tendency for genres to harden and become less innovative as an industry matures, indicates how media content is inseparable from the economic and structural conditions in which it is produced and circulates. Social change needs to be pursued at all levels of the circuit of production, distribution and consumption (Gay et al., 1997), a daunting task for anyone aiming to transform the relations between technology, social stratification, and learning. Industry analysis reveals the weight of existing market segments and distribution mechanisms. And at the other end of the circuit, we know from audience studies that the content of a title does not fully determine local uptake; this disjuncture is even more pronounced in the case of interactive media. The intentionality of the designers is far from determining the ways in which the media artifact will circulate and be taken up by particular contexts of engagement. The everyday anxieties and assessments of parents and children and the contemporary demands of childhood dictate that competitive academic achievement is more directly tied to recognitions of success than exploratory intellectual play.

Grade-based educational software appeals to middle-class parents' desires for wholesome, creative, and interactive play for their children, that also gives them a leg up on subjects that will be covered in school. Unlike action games, which are marketed directly to children on television and in gaming magazines, educational software is marketed towards parents and appears in magazines such as Family PC. One ad for Knowledge Adventure's JumpStart software series (figure 1), which ran in the December 2000 edition of Family PC, sets up an unambiguous relation between the products and academic achievement. A blond school-aged girl dressed neatly in white knee-high socks, Mary Janes, and a red skirt, still wearing her backpack, stands with her back to you (your child here), clutching a school worksheet. The sanitized space of the large kitchen and the girl's appearance code the home as White, suburban, conservative, and middleclass. The girl faces a refrigerator already overflowing with assignments red-inked with 
gushing teacher notes: stars, "Good Work!" and "Excellent!" The backpack, the school assignments, and the voice of assessment are represented in a central role in the intimate sphere of the home. A drawing of mom, posted in the visually prominent area at the top left, hails the parent in charge of children-related purchases. She is a smiling blond mother with curly hair and rosy cheeks.

The ad copy describes the current concern with self-esteem and identity in promoting academic achievement: "When kids succeed, they feel confident. When they feel confident, they succeed. This is how JumpStart works. And why so many parents think it's the best learning software you can buy." In contrast to the other ads in this campaign, this one features a girl, and has ad copy that specifically poses self-esteem issues. Together with the aggressive posture of the girl with hands on her hips, looking upwards, the ad implies that the software will address the inequities that have plagued girls in academic achievement. The software provides a jump start for stalled children in the academic rat race, mobilizing the metaphor of "education as a race" which dominates the culture of competition of elite schooling in the US (Varenne, Goldman \& McDermott, 1998, pp. 106-115). The ad campaign's tagline - "She's a JumpStart Kid, all right" - is subtly crafted to imply a status distinction with other kids, the perpetually stalled failures that don't use this software. The phrase "all right" is a reassuring confirmation of the parental conviction that their child is inherently smart and deserving of this status. Your child, too, may be deserving of higher recognitions of success than she is currently receiving.

These ads target increasingly younger children with their toddler and preschool titles, as well as working to fill leisure time with the competitive logic of academics. Another ad in this campaign features a smiling, sleeping boy in a bed covered in books with titles like "Ships", "Vikings", and "The Stars". The books are even tucked into his bed sheets, replacing the stuffed animal so iconic of childhood attachments and imaginings. He is presumably integrating academic content with his dream work. Another JumpStart kid appears in an ad waking up a bleary-eyed father at the crack of dawn, again with a backpack on and lunchbox in hand. These kids have internalized the disciplines of schooling, reluctant to take their backpacks off and eager to get them back on. They are represented as deeply identifying not only with academic content but the aggressive, forward and upward competitive habitus of upper middle-class success.

Insert Figure 1 here

Corporations market software as a vehicle for academic success to parents, who in turn market academics as an entertainment activity to their kids. The ads for the Math Blaster series feature children in moments of ecstatic play, swimming or playing superheroes, with thought balloons describing the mathematical significance of their play (figure 2). A tiny cape crusader speculates, "If I fly 90 miles an hour and the earth is 24,902 miles around, can I still get back home for breakfast?" "Must be the Math Blaster" ${ }^{\circledR}$ " suggests that ad copy below. "Software that gets your kids into math. And math into them." This is the currently dominant logic of edutainment: The most effective forms of learning are fun. So let's package tasks that function to measure and sort children into something that is pleasurable. That way, the kids will have fun, they will also get ahead in life, and parents can feel they have fulfilled the impossible imperatives of contemporary middle- 
class parenting that says they must support competitive successes and disciplines while also keeping their children perpetually happy and entertained. This is a "sugar-coating" philosophy that many game designers critique in current game design, but which is perpetuated by the logic of the marketplace (Bruckman, 1999). These are the discourses that frame the production and marketing of edutainment products. Their mobilization in everyday practice, however, involves a complex series of negotiations between the social agendas of kids and adults, and it is to this context of play that I would like to turn to now.

Insert Figure 2 here

\section{The Consumption Setting: Software and activity in the 5thD}

My research on play with children's software was conducted as part of a three-year, collaborative ethnographic evaluation effort examining the 5 thD reform effort where we analyzed fieldnotes and videotape from three 5 thD clubs. The 5 thD is an activity system where elementary-aged children and undergraduates from a local university come together to play with a diverse range of educational software in an informal afterschool setting. The clubs are located at community institutions such as Boys' and Girls' Clubs, schools, or libraries and vary considerably depending on the local context and institution. What is common across the settings is a commitment to a collaborative and childcentered approach to learning, the non-hierarchical mixing of participants of different ages, and the use of personal computers running software designed for children. Interactions between kids, their undergraduate mentors, and educational games was documented through fieldnotes by the undergraduates and videotaping of interactions on and around the computer by the research team that I was part of. Our team conducted videotaping and observations at three different sites in Southern California, where kids, researchers, and undergraduates gathered every weekday through the school year. In the site that is the focus of this paper, many kids would filter in and out of the computer area, but there was generally a stable group of regulars that saw the computer club as their primary focus of activity in the after school center that included opportunities for sports, crafts, and other kinds of games.

Edutainment games from companies like Knowledge Adventure and TLC were a mainstay of the 5 thD clubs. In the late nineties, when I was conducting my fieldwork, the clubs still ran copies of games that McCormick had been involved in such as Gertrude's Puzzles on old Apple IIs, and as they upgraded their machines to more sophisticated models, they continued to purchase and utilize more recent titles. The grade-based systems such as JumpStart were yet to make an appearance, but there were products that relied on a similar adventure-puzzle format. During my fieldwork, a new game, The Island of Dr. Brain, was introduced, which was played from a CD-ROM and had more sophisticated graphics than the earlier adventure puzzle games being used at the club. Here I use Dr. Brain as an example typifying the content and play dynamics of the edutainment genre.

The Island of Dr. Brain involves an adventure game scenario where the player is working as Dr. Brain's lab assistant to recover a special battery from his secret island. The player proceeds by solving puzzles based on science, math, logic, and other schoollike subject matters. For example, in the entrance chamber, one clicks on a microscope to 
solve an algebra problem to sort some microorganisms along $\mathrm{x}, \mathrm{y}$ axes, a number series problem to open a sarcophagus, and the Tower of Hanoi puzzle to open the door to the chamber. The narrative trajectory of the game is sequential and single-track; there is only one pathway through the island, and getting to any given puzzle is contingent on solving puzzles preceding it. The fantasy scenario furnishes a narrative coherence and goal orientation to a series of otherwise unrelated problems. This dual structure maps onto how entertainment and educational idioms are embedded into the game. Each exploratory scene in the fantasy scenario functions like an animated storybook, with "hot" areas that trigger either an animation, dialog box, or puzzle. While players can explore the storybook scenes in an unmonitored and open-ended way, these exploratory moments are coded as silly and functionally inconsequential, transitional "down times" between the "real work" of solving serious academic problems. The puzzles are the real "content" of the game, and solving them is rewarded by gold and bronze plaques, and tallied into a final score at the end of the game. The game even provides extra credit points for kids who solve additional problems. Unlike school, however, negative assessments are muted in encouraging messages such as "try again!" The game mobilizes idioms of educational achievement outside of the sorting functions of educational institutions, becoming an arena for boosting academic self-esteem without fear of consequential failure.

The Island of Dr. Brain was remarkably popular in the 5 thD during my period of fieldwork. Overall, kids responded positively to the eye-catching graphics and animations, and oriented quickly to the linear goal structure of the game. Puzzles at the novice level were doable with some help for all of the kids we have observed on tape; the game skirts the edge of kid expertise, inviting productive collaboration with adult participants. The undergraduate fieldnotes describe the game as "challenging", "impressive", "a thought-provoking game", school-like, and with "obvious" educational value. One undergraduate also pointed to the "diversity of tasks" as an important feature of the game in making it interesting and appealing to different kids. Kids' descriptive discourse about the puzzles focuses on whether the game is "hard" or "easy". This kind of discourse contrasts to other forms of gaming that might be described along a spectrum of "cool" versus "boring". When playing Dr. Brain, "cool" was used only to describe elements from the exploratory scenes and animations, never the puzzles themselves.

The game calls out the often latent tensions between the educational philosophy of the 5thD and the educational philosophy of mainstream school achivement, particularly in the difficulty of recognizing and managing dominant social markers such as "smartness" and "success". In the fieldnotes and videotapes of play, three salient dynamics emerge, which are linked to these tensions regarding the value of the game in a setting like the 5 thD. First, is the way in which entertainment and education idioms are incorporated into the game as fundamentally disjunctive forms of engagement. Another is the tension between the orientation of kids, who want to get through the tasks in as expedient a manner as possible, and the orientation of adult helpers, who try to get kids to understand the nature of the problem. Third, is the way in which the game invites a competitive orientation through explicit achievement recognitions in the game and knowledge and achievement displays by the kids.

\section{Participation Genres: Getting ahead, achievement, and knowledge display}

Competition is a basic feature of all game-oriented children's software, but games such as Dr. Brain that have clear parameters for competition, well-defined obstacles, and 
unambiguous recognitions of success, invite the most dogged orientation toward winning, often at the expense of actually mastering or making sense of the content embedded in the game. This is the peculiarly academic brand of competition as it is translated to a recreational domain that is not immediately consequential for sorting or assessment performed by educational institutions and testing. As Shelley Goldman has described in her ethnography of an elite school (Goldman \& McDermott, 1987), this logic applies to-

the paradoxical concerns of those who are most likely to succeed with altogether inconsequential competitions. It is the story of ... intense work constructing competition. Continual quizzes, tests, exams, special project, sports events, and so on produce complex ranking that are displayed in plaques, trophies, special citations. Individual qualities become public events. (Varenne \& McDermott, 1998, p. 18)

The Island of Dr. Brain is part of this cultural construction and display of a form of competition that is institutionally separate from schooling, but is tied to a related discourse and habitus of achievement. The game has clear endings to each puzzle, where kids receive a plaque, keyed to different levels (bronze for novice, silver for intermediate, and gold for advanced). Kids can view these plaques on a progress chart throughout the game, and the game tallies their overall score once they have traveled through the entire island. Game play is punctuated by these small recognitions of achievement, which kids will point out to their partners if they haven't noticed, or, if they are playing alone, may even call out to others at other parts of the club. Although these are "token" achievements, they still matter to the kids. One undergraduate writes: "Dr. Brain kept on giving [the boy] bronze awards. [He] kept on saying that this kind of sucked. Why couldn't he get better than bronze, like silver or gold? He wanted better awards." One boy, working alone, with the site coordinator's occasional help, is struggling with a particularly difficult problem, and finally solves it, apparently by repeatedly guessing. He gleefully shouts, "Yes! I did it!" calling out the site coordinator's game. "I got it! I got it!" he continues to shout, dragging two other kids to the computer to show them. "I did it!"

The awareness of game content is peripheral to awareness of the structure of the problem domain, just as the overall fantasy scenario is incidental to the puzzles. While all of the puzzles exhibit some kind of "brainy" content: chemistry, math, art appreciation, etc., many can be solved tactically, based on the logical consistency of the problem domain, rather than with recourse to extra-textual stores of knowledge. There is almost no discussion of the topics that form the game content (i.e., the nature of algebra problems, what a microchip does, what a dominant and recessive gene is, etc.). In many cases, the puzzle is self-explanatory or recognizable from other game or test situations: a hidden figures puzzle, a matching game, a word search puzzle, a number sequence puzzle, a jigsaw puzzle, or magic squares. In other cases, the structure of the problem emerges after clicking on some elements of the puzzle and through trial and error. For example, one problem asks for changes to an algebra equation to change the lines on a set of $x, y$ axes. After clicking the numbers in the equation up and down, kids quickly figure out the relationship between the equation and the line on the graph, and the problem is soon solved. In still other cases, the structure of the problem is more opaque, and invites recourse to the hint watch or rereading of the instructions, as well as enlistment of help from other club participants. Regardless of the difficulty of recognizing the general nature of the task, overall engagement time with the puzzle is almost always dominated by trying to figure out the structure of the problem. 
In the 5 thD, these features of the game play out in practice as a tension between kids, who prioritize winning, and undergraduates, who prioritize mastery of content. In other words, for kids, winning matters more than how you play the game, especially when playing against a stubborn machine. Computer games don't account for or acknowledge how the kids play the game beyond the specific inputs at the interface, and thus can invite a focused orientation to achieving these formal conditions for winning, at the expense of understanding of more fundamental content understanding. The undergraduates have been instructed to "provide the children with as little help as possible, but as much help as necessary to ensure that both the students and the children have a good time" (Cole, 1997). This rule of thumb for pedagogy in the 5 thD is an application of Vygotsky's theory of the Zone of Proximal Development, which posits that learning happens as an interaction between experts and novices engaged in joint activity. In their fieldnotes, undergraduates describe their interaction, and work to exhibit their application of these educational principles. One representative note from an undergraduate describes how she provided just enough information to help her partner move ahead in the task.

Some of the language was very complex, and I helped him by telling him what the words meant. I would just give him the meaning of one of the words that needed to be replaced, and if he didn't know what the other words meant, I would give him pointers on their general meaning, or use them in a sentence, so he could figure them out for himself.

In contrast to this stance by adults, who feel it is important to provide the minimal amount of help, kids seem to have no reservations about giving the answers directly to other kids. On a subsequent day, a younger boy, Chris, is playing Dr. Brain, and anther boy, Roger shows up to dictate exactly what to input, with no explanation of the actual process. Chris has just begun a new problem involving programming a robot to move through the laboratory and pick up a silver key. Roger shows up, declares his expertise, and then tells Chris what to do. The remainder of the problem solving sequence, until they arrive at the desired end state (to get the key), is exclusively about Roger dictating operations, while Chris inputs them.

$$
\begin{aligned}
& A=\text { Roger } \\
& C=\text { Chris }
\end{aligned}
$$

1 R: Allright, go in.

2 C: Here we go.

3 R: I'm very good at this.

4 C: There was the earthquake. Now what do we want to do?

$5 \quad \mathrm{R}$ : Take the purple one.

6 (C picks up purple chip.)

$7 \quad$ R: Put it in the back of his head.

8 C: Right there? (Puts it in robot's head.)

9 R: Yeah. OK, let me do this.

10 C: We know how to...

11 R: I'm really good at this.

12 C: OK, hint watch. (Hits hint, which turns position indicator on.)

13 R: Hint watch. OK, robot position indicator. 
17 R: Forward, left, forward, forward, forward, forward, stay, stay, stay. Pick it up. Pick up. Now right, right, forward, forward, forward, right, forward, forward, drop. Now run. I mean go. Do go.

18 (Inputs program as Roger dictates. Runs program, and robot gets a silver key.)

19 R: There he goes. OK.

20 C: Silver key.

In this sequence, Roger begins by telling Chris how to activate the puzzle (lines 5, 7), and then dictates the answers as Chris inputs them (lines 15, 16, 17). The jointly formulated goal of the two kids is to get through the problem as quickly as possible rather than to explicate content knowledge for Chris, who blindly follows Roger's instructions. Both of these sequences, while based on different priorities between kids and adults, are similarly an outcome of a linear and singular goal orientation embedded in The Island of Dr. Brain. On a different day, Roger takes this position with another girl playing the game for the first time. The undergraduate working with her is upset by this, and writes an unusually critical fieldnote.

She was not learning to solve these problems on her own. He wouldn't tell her the point of the game, or how he was figuring out these solutions, he just commanded her. I guess he saw the goal as getting to the next level, no matter what. It did not matter if she understood or not.

The higher priority that adults give to process and understanding also translates into a tension between an explicit instruction-driven orientation and a trial and error, guessing orientation. The adults tent to stand in for the former orientation and the kids for the latter, particularly when they are not working under close adult supervision. Unless held back by an adult, kids almost always click quickly through the instructions, and will invariably look to the hint watch for partial answers before they will try reading the instructions for explicit directions. As one undergraduate writes, "When we would get to each new puzzle he did not bother to read all of the directions. I was inclined to read each sentence carefully trying to remember what it said and go through all of the directions before starting each task."

Unlike simulation, strategy, and scenario games, edutainment adventure games such as Dr. Brain require a narrowly defined set of correct inputs in order to proceed through the game. There are clear right and wrong answers, and winning conditions are assessed only based on these answers to a series of problems. The kids express satisfaction and even glee at "outwitting" the game, while adults try to steer them toward solving the problem without guessing. Much of this orientation is over-determined by the fact that puzzle completion affords immediate progression to another puzzle rather than continued engagement with a given content domain. When a puzzle is completed, the computer responds with a plaque of achievement, and moves quickly to an entirely different challenge. The clear and stable standards determined by the game channels game play toward well-defined goals and invites celebration and knowledge display upon achieving those goals. As they work to build kids' confidence in their intelligence and abilities, undergraduates also reinforce and produce these displays of achievement. 
Adults and the game perform academic achievement in a context that is relaxed, enjoyable, and rich with peer group interaction, strengthening kids' identification with academic content. At the same time, the game is also in tension with the philosophy of the 5 thD that encourages collaborative and non-competitive learning processes. These tensions become visible in the case of one boy's engagement with the game.

\section{Roger on the Island of Dr. Brain}

A closer look at one boy, Roger, and his play with The Island of Dr. Brain illustrates some of the achievement-oriented investments and subject formation that the game invites. Roger has already appeared in earlier examples as a game expert that often appears over the shoulder of other kids giving answers to the puzzles. He has a reputation at the club as academically competent, especially in the area of computer literacy. After his completion of the game, Roger becomes known at the club as an expert at The Island of Dr. Brain, and appears frequently in subsequent tapes of the game, helping or heckling other kids. Roger provides a good case for observing a child who orients quickly to the achievement goals and academic content. His relation to Dr. Brain exemplifies many dynamics of edutainment as a genre of participation. The video record provides more detail on how Roger engages with the game and others at the club. The first set of examples is from the day when Roger completes the whole game sequence of The Island of Dr. Brain during one club period. He has played bits and pieces of the game previously with other kids, but this is the first day in which he gets sustained time with the game, and, with adult help, moves through puzzle after puzzle. In this first example, Roger has just begun to work on a puzzle which involves identifying the chemical code for elements in a set of objects, a tin cup, a zinc bar, etc. (figure 3 ). When the puzzle pops up, he reads the instructions, and then tries clicking around to determine the nature of the task. The adults he has been working with have been temporarily discussing other matters, but he calls them back to the task with a question:

Insert Figure 3 here

$$
\begin{aligned}
& A=\text { Roger } \\
& \text { Ad }=\text { Adult } \\
& S C=\text { Site Coordinator }
\end{aligned}
$$

1 R: What am I supposed to do? I don't get this.

2 SC: OK did you analyze it? It says: "These chemical elements ..."

3 R: (Pulls down another screen of directions and reads, moving pointer over lines.)

4 SC: Oh, you're doing trace elements OK, here.

5 R: Ahhhh! I see. (Starts to read the description of the element to find. The object under question is a zinc bar.)

6 Ad: Oh, do you get the hints?

7 SC: "Blank" -oxide (referring to the description, which gives a hint that the answer is a " oxide").

8 R: Carbon. Blank? Blank? 
Ad: See the blank here? (Points to screen.) They're saying fill in the blank.

10 R: Yeah, I know.

11 SC: It's like the sun block people put on their face ... You know, people put it on their nose ...

12 R: Yeah what is it?

13 SC: What is it called?

14 R: SPF.

15 SC: No. There's a thing that completely blocks it out.

16 R: What? Blank?

17 SC: Zinc-oxide, maybe?

18 R: Ziiiinc...

19 SC: Have you ever heard of that?

20 R: (Nods.)

21 SC: It's the really white stuff. So you have to find that.

22 R: What's the "Z"? (Points to "Z" in table of elements.)

23 SC: Go up one. That's the zinc. See it up on top?

24 R: (Selects $Z$ for zinc, and gets the first element identified correctly.) Allright.

25 SC: OK. Now you're doing the next one. It's two percent. It says: "These chemicals are present only in minute amounts. The analyzer cannot trace them." So, that's the hint you got before, which is the trace element, which means there wasn't enough of them to pick up.

26 R: (Selects "Trace Element" and successfully completes analysis of the first object.) Allllright. Zinc Bar ... (Places zinc bar to the side, and puts tin cup in the analyzer.) This is tin. I know it already. Tin ...

In this sequence of activity, Roger orients quickly to the suggested task structure of the overall game for a new problem: read the directions, determine what the problem is, get the correct answer to the problem, and display knowledge. The call to action by the game is: process procedure, execute procedure, solve problem, record solution (fill in the blank). When Roger falters in determining the procedure, he enlists the help of the adults: "What am I supposed to do? I don't get this" (line 1). Roger and the site coordinator orient to the instructions, and then, the initial recognition occurs, "Ahhh. I see" (line 5), as he is able to decode the instructions and recognize the call for action. Both Roger and the site coordinator then shift their orientation toward the content domain and solving the problem: What kind of oxide is it? (lines 7-10). They need to fill in the blank, the invitation by the game to respond to a pre-programmed structure of meaning. The site coordinator, then, tries to get Roger to fill in the answer, by providing some hints, though she eventually must give him the answer: zinc (lines 11-17). Roger responds with another act of recognition: "Ziiinc," in an extended, low tone, and nodding to the site coordinator's confirmation that he understands the answer (lines 18, 20). He thus positions himself as the subject, who has responded to the call for a particular answer. For the remainder of the clip, she guides him in locating zinc on the list of elements, and he inputs the answer: "Allright" (line 24).

This mode of interaction with the puzzles, where Roger decodes the instructions, executes them in solving the puzzle, completes the puzzle, and moves quickly on to the next, is typical of his engagement throughout most of the game. As he works through a 
puzzle, each successfully completed step is punctuated by an "Allright," or "Ahhh!" of recognition. In this way, he repeatedly enacts the subjectivity and habitus of one whose knowledge and competence is being tested and assessed, orienting to a participation genre of academic performance. Roger's brief utterances of recognition are subtle but repeated frequently. On other occasions, Roger makes more explicit statements that point to his increasing subjectification in the terms of academic achievement as suggested by the game. In the following clip, from the same day as the previous clip, Roger has just completed the Tower of Hanoi problem in The Island of Dr. Brain. His adult partner has been engaged with another child while he works on the puzzle, and he tries to draw her attention to the fact that he has solved the puzzle, self identifying himself as a "smooth" problem solver, displaying his competence:

$$
\begin{aligned}
& A=\text { Roger } \\
& A d=\text { Adult }
\end{aligned}
$$

R: $\quad$ Now I have it solved! (Turns to adult who is still preoccupied with other child.) I got it solved ...

Computer: Congratulations! You've earned a bronze logic sequence prize!

R: (Still trying to get adult's attention) I did it ...

Ad: (Turns back to Roger.) Sweet.

R: I'm smoooooth.

Ad: How many moves did you do it in?

R: $\quad$ Seventeen.

Roger is a particularly adept strategist in getting correct answers although he might not understand the underlying problem domain. In many instances of his play, I have marveled at how he was able to quickly identify the minimal conditions for solving a task, delegating as much problem solving effort as possible to other helpers in the vicinity, and getting through the problem. This next example is from one of the first instances of Roger's exposure to Island of Dr. Brain. Roger is working with another kid, Herbert, and they are just beginning "the rat-driven elevator" problem (figure 4). The site coordinator occasionally checks in on their play. This is the first time for either of them to encounter this problem, and they are exploring and trying to decode the problem space. The task is a complex one. They are asked to determine how many spokes on two different gears are required to balance a counterweight with the weight of the elevator. They spend quite some time keying in different answers and trying to figure out the nature of the problem, enlisting the site coordinator's help. They try various solutions, but the elevator continues to either fly into the ceiling or the floor, toppling the crash-test dummy inside. Eventually, they begin to enjoy simply watching the dummy crash time after time, moving from a moment away from an achievement orientation to pleasure in this spectacle. After almost ten minutes, in which they continue their trial and error tactics, they finally happen on the correct answer. This excerpt is of this concluding sequence:

$$
\begin{aligned}
& R=\text { Roger } \\
& H=\text { Herbert } \\
& S C=\text { Site Coordinator }
\end{aligned}
$$


1 R: OK, fifty-six. Fifty-one and seventeen. You have seventeen and fortyeight. Forty-eight. OK let's try it.

2 H: Yeah.

3 R: I love doing this.

$4 \quad H$ : Yeah this is it. Yep. Nope. Nope.

(Elevator crashes.)

$5 \quad \mathrm{R}:$ Ahhh!! I love that.

6 H: It must, it must be fifty-one. Oh, man.

7 R: This is so hard.

8 H: Eighteen teeth. Watch this, watch this. Watch this.

9 R: You think this is right? No, he got tired. (Elevator crashes.) Ahh!!! (Laughs.) I love this!!

10 H: Eight, twenty-one. Nooo!!!!

(Elevator crashes.)

11 R: I love doing this.

12 H: Thirteen. Yeah. (Elevator is lowered successfully.) Oh my gosh. We got it. We got it!!! Yeah, [site coordinator name]. We got it.

13 SC: Allright!

14 R: And we did it by guessing too!

15 H: I know, huh!

16 R: We're so good. Yeah, we can ride it.

17 H: Yeah.

Insert Figure 4 here

This clip records a gleeful moment, with Herbert calling out to the site coordinator about their accomplishment, and the two boys mutually congratulating themselves (lines 1216). While they are still proceeding along the sequential logic of the game, they have managed to claim a small space of achievement for themselves, which is not tied to the procedure for action as suggested by the explicit educational goals of the game. They are still, provisionally, heeding the call to action: working on decoding the instructions and getting the correct answer. Most importantly, they persevere and achieve mastery, at least in the technical terms defined by the game, which are exclusively about keying in the correct answer to a problem. They are particularly happy at having "tricked the system" by getting the right answer by guessing. Far from detracting from their sense of mastery, this accomplishment serves as a display of achievement. "We're so good. Yeah, we can ride it." In a subsequent day, Roger revisits the same problem, and mobilizes the guessing tactic that he developed with Herbert, abandoning any attempts to decode the nature of the problem and reproducing the guessing heuristic in another context. Although the adult helper he is working with tries to get him to solve the problem by dividing the elevator weight by the counterweight, he insists on guessing instead, "I have no idea. I'm just guessing. It works!"

A few months later, Roger is well established as the site expert on The Island of Dr. Brain. I have already described instances of him checking in on other kids' play of 
the game displaying his knowledge and giving answers. Roger is repeatedly hailed as a particular kind of learner by the game and others at the club, and repeatedly recognizes the hail, and subjectifies himself to this shared sociotechnical formation (Althusser, 1969). Insofar as Roger has become identified and self-identifies as an expert at this game at the club, his mode of engagement stands out from that of other children. Yet as seen in the other instances of kids engaging with and learning from Roger around $D r$. Brain his orientation to beating the game is one that other kids quickly model. Despite adult efforts to redirect engagement towards a more content-oriented and less goaldirected model of play, the multimedia genre embedded in the game and existing genres of participation tend to override their ongoing interference patterns and reform-minded orientation.

\section{Conclusions}

While the cases of engagement with Dr. Brain that I have described may not represent ideal kinds of learning outcomes for a setting like the $5 \mathrm{thD}$, they do represent successful genre recognitions by children that tie together sites of consumption and production; players recognize themselves in the genre suggested by the designers and marketed by advertisers. Just as the reform-oriented educators of the 5thD struggle on a daily basis to introduce new kinds of participation genres into the already densely structured lives of children, software designers have struggled to introduce and promulgate new idioms of engagement through innovation in media artifacts. Other software titles do more to suggest alternatives to school-oriented models of progress and achievement (Ito, 2003; 2004), but it is a constant struggle to deconstruct genres of entertainment and education which society and culture have drawn in firm opposition to one another, with different styles, institutions, and genres of participation. Middle-class children correctly identify schooling (oriented to participation adult-defined achievement goals) and recreation (oriented towards peer-group participation) as the primary structures defining their social success. When presented with a title like Dr. Brain, they are quick to recognize a schooloriented genre of media and participation, since the genre is reinforced settings and institutions distributed across the circuit of culture.

Children engaging with Dr. Brain participate in a genre of academic preparatory play that Hervé Varenne, Shelley Goldman, and Ray McDermott (1998) have framed as typical practice in upper-middle class schools. They describe a question and answer game called "Screw Thy Neighbor" played at an elite middle school, where kids cover school topics, translated to a quiz-show genre. They conclude that compared to standardized testing, "'Screw Thy Neighbor', like the Balinese cockfight, does not do anything. Functionally, it is 'just' deep play, and culturally, it is the stuff of life" (1998, pp. 112-113). In the words of one of the teachers: "You make it into a contest, and suddenly everyone wants to be an expert at defining vocabulary words" (p. 114). Varenne and his colleagues write, "In their vocabulary, they say simply that the competitions of everyday life are 'fun'. Competition transforms the boring into the interesting" (p. 114). Games such as "Screw Thy Neighbor" and Dr. Brain are preparatory for "real" school tests and productive of a competitive, success-oriented habitus.

Early edutainment developers hoped to put accessible technical tools in the hands of the disenfranchised, alleviating the oppressiveness of dominant notions of education. Software has become another site for addressing achievement anxiety in parents, and for instilling the habitus of upwardly-mobile achievement for children that seem to have been 
born into success. Reform efforts that rely on educational media must produce innovative content as well as innovate in distribution mechanisms and contexts of reception to have systemic impact. Although I have stressed the conservative tendencies of genres, the circuit of culture I have described also suggests multiple points of negotiation, juncture, and disjuncture. The ongoing contestations between genres of participation and representation suggest ways of reshaping and appropriating the categories of education and entertainment that have been handed down to us. Educational institutions continue to have a determining effect on how childhood success and achievement is measured even outside the classroom; the case of edutainment demonstrates the ways in which genres of education migrate and morph beyond the institutional boundary of school. Contexts of play and informal learning, while seemingly marginal to the high-stakes contestations over educational sorting and achievement, are sites that demonstrate the alignments and disjunctures between the cultural and social structures of children's lives. It is when these sites of reception can join hands with software creators and distributors across the circuit of culture, that we can begin to imagine alternative genres of participation that are both compelling and sustainable.

\section{Acknowledgements}

The ethnographic research for this paper was conducted as part of a project funded by the Mellon RussellSage Foundation and benefited from being part of the broader $5^{\text {th }}$ Dimension research effort. Writing was funded in part by a Spencer Dissertation Fellowship and the Annenberg Center for Communication and the University of Southern California. This paper is excerpted from a dissertation for Stanford University's Department of Anthropology, entitled Engineering Play which benefited from readings and comments by Carol Delaney, Joan Fujimura, Shelley Goldman, James Greeno, Purnima Mankekar, Ray McDermott, Susan Newman, Lucy Suchman, and Sylvia Yanagisako. The description of the history of the children's software industry was drawn from interviews with software developers. I would, in particular, like to acknowledge the help and insight of Ann McCormick.

\section{NOTES}

1 Quotes from McCormick are from an interview conducted by the author.

2 The assumption that television viewing is "passive" and regressive has been roundly criticized by scholars who examine the class dynamics of children's media consumption. Seiter's (work $(1995,1999)$ advances one of the strongest arguments for this position. In addition, other scholars have argued that the interpretation of television is a creative and cognitively complex process comparable to how young people engage with more highbrow media forms (Hodge and Tripp 1986; Dyson 1997).

\section{References}

Althusser, L. (1969). Ideology and state apparatuses (B. Brewster, Trans.). In Lenin and philosophy and other essays by Louis Althusser (1971 ed.) (pp. 127-188). New York: Monthly Review Press.

Brown, J. S., \& Duguid, P. (1996). Keeping it simple. In T. Winograd (Ed.), Bringing design to software. Retrieved from http://www.johnseelybrown.com/keepingitsimple.html, on March 13, 2006. 
Bruckman, A. (1999). Can educational be fun? Paper presented at the Computer Games Developers Conference, San Jose, March 15-19.

Cole, M. (1997). Cultural psychology: A once and future discipline. Cambridge: Harvard University Press. Cross, G. (1997). Kids'stuff: Toys and the changing world of american childhood. Cambridge: Harvard University Press.

Dyson, A. H. (1007). Writing superheroes: Contemporary childhood, popular culture, and classroom literacy. New York: Teacher's College Press.

Gay, P. d., Hall, S., Janes, L., Mackay, H., \& Negus, K. (1997). Doing cultural studies: The story of the sony walkman. Thousand Oaks: Sage.

Goldman, S., \& McDermott, R. (1987). The culture of competition in American schools. In G. Spindler (Ed.), Education and cultural process: Anthropological approaches, second edition (pp. 282-300). Prospect Heights, IL: Waveland Press.

Hodge, B. and Tripp, D. (1986). Chidlren and television. Stanford: Stanford University Press.

Ito, M. (2003). Engineering play: Children's software and the productions of everyday life. Stanford University, Stanford.

Ito, M. (2004). Mobilizing fun in the production and consumption of children's software. The Annals of the American Academy of Political and Social Science, 597 (1), 82-102.

Revue, C. s. S. (1997, June/July 1997). A conversation with Jan Davidson. Children's Software Review, 25.

Seiter, E. (1995). Sold separately: Parents and children in consumer culture. New Brunswick: Rutgers University Press.

Seiter, E. (1999). Power rangers at preschool: Negotiating media in child care settings. In M. Kinder (Ed.), Kids' media culture (pp. 239-262). Durham: Duke University Press.

Varenne, H., Goldman, S., \& McDermott, R. (1998). Racing in place. In H. Varenne \& R. McDermott (Eds.), Successful failure: The school America builds (pp. 106-128). Boulder: Westview.

Varenne, H., \& McDermott, R. (1998). Successful failure: The school America builds. Boulder: Westview Press. 